\title{
Induced preference for morphine in rats
}

\author{
JOSEPH W. TERNES \\ Caribbean Primate Research Center, University of Puerto, Rico \\ Sabana Seco, Puerto Rico 00794
}

\begin{abstract}
A simple procedure for the induction of morphine dependency in rats is described. Two groups of 15 Wistar strain rats were given weak solutions of morphine in water $(.3 \mathrm{mg} / \mathrm{ml})$ as their only source of liquid for either 84 or 60 days. Subsequently, both groups were given a two-bottle preference test between morphine solution and vehicle for 8 days. Results indicated that the 84 -day exposure group drank significantly more morphine than the 60-day exposure group. Both groups drank more than $50 \%$ of their total fluid intake in the form of morphine solution, however, only the mean of the 84-day exposure group was significantly different from 50\%. It was concluded that morphine dependency, indicated by the self-selection of morphine, was induced by forcing consumption of weak solutions of morphine for 12 weeks. The results are discussed as an example of unprepared learning.
\end{abstract}

Rats have been used extensively as an experimental model of opiate dependence (Beach, 1957; Martin, Wikler, Eades, \& Pescor, 1963; Weeks, 1962). Methods for inducing morphine dependence generally fall into three categories: daily peritoneal administration (Hanna, 1960; Seevers \& Deneau, 1963); surgical implantation of slow dissolving pellets (Huidobro, Huidobro, \& Lorrain, 1968; Maggeolo \& Huidobro, 1961; Wei, 1973); and oral injestion (Khavari \& Risner, 1973; Stolerman \& Kuman, 1970; Thompson \& Ostland, 1965).

The oral technique offers considerable advantage over other methods because of its simplicity. Since it requires neither special individual handling of subjects nor special equipment, simultaneous testing of large numbers of subjects is feasible. Additionally, it is an uncontrived method of self-administration of the drug. The oral route has not been widely used, however, because of the commonly held notion that the bitter taste of the opiate alkaloid limits the ingestion of morphine to quantities which are insufficent for the induction of dependence. Wikler, Green, Smith, and Pescor (1960) and Wikler, Pescor, Miller, and Norrel (1971) have avoided this problem by substituting etonitazene for morphine. Khavari and Risner (1973) have successfully masked the taste of morphine with a $10 \%$ sucrose vehicle. Nicholes and Davis (1959) used a combination of injections and forced drinking of morphine $(.5 \mathrm{mg} / \mathrm{ml})$ to induce rats to increase their consumption in subsequent tests of preference between morphine and water. Kumar, Steinberg, and Stolerman (1968) reported that it was possible to dispense with the morphine injections altogether and still produce a preference for morphine. Their method involved training rats to satisfy their thirst in a 7-h period daily. Then they substituted morphine solution $(.5 \mathrm{mg} / \mathrm{ml})$ for water during this period. Preference was measured in terms of the proportion of morphine solution drunk when both morphine and water were made available concurrently.
Later Stolerman and Kumar (1970) reported that the bitter taste of morphine solution $(.5 \mathrm{mg} / \mathrm{ml})$ had acquired secondary reinforcing properties in dependent rats which were given morphine to drink after the onset of withdrawal symptoms. They concluded that, under special training regimes, rats can learn to overcome their initial aversion to drinking morphine solution. However, when Khavari and Risner (1973) gave rats a $.5 \mathrm{mg} / \mathrm{ml}$ solution of morpine in tap water as their only source of liquid, no preference was developed after 50 days. Rather, the rats generally rejected the drugged solution when an unadulterated alternative (tap water) was also made available. Moreover, by abstaining from the drug, the rats induced withdrawal symptoms. The occurrence of these symptoms was interpreted as evidence that a physical dependence upon morphine had been developed in the rats by means of the forced drinking procedure. The implication, however, was that psychological dependence, which is usually inferred from active arug seeking behavior, e.g., selection of the morphine alternative over tap water in a two-bottle choice test, was missing.

The present experiment demonstrates a simple procedure for the induction of morphine dependence in rats. Dependence was defined as the acquired preference for unadulterated, though weak, solutions of morphine $(.3 \mathrm{mg} / \mathrm{ml})$ in tap water. Morphine preference was measured by the proportion of morphine solution drunk when both morphine solution and water were made concurrently available after either 60 or 84 days during which morphine solution was the only available liquid.

\section{METHOD}

\section{Subjects}

Thirty Wistar strain male rats approximately 95 days old at the start of the experiment served as subjects. The were held in standard Hoeltge wire rat cages and housed in an open-air animal shelter at the Caribbean Primate Research Center, Sabana Seca, 
Puerto Rico. Although the enclosure provided cover from direct sun and rain, there were no walls as such. Thus the subjects experienced the natural light and temperature cycles prevailing during the months of February, March, and April.

\section{Procedure}

After a 2-week period to allow for adaption and synchronization to their new environment, the subjects were separated at random into two groups of 15 rats each.

Group 1. Subjects were placed on ad-lib food (Purina Monkey Chow) and a solution of .3-mg morphine sulfate/ml tap water. The solution was presented in $300-\mathrm{ml}$ water bottles with standard lick tubes and rubber stoppers. No other source of liquid was provided. After 84 days, the induction phase was terminated and a two-bottle preference test between $.3 \mathrm{mg} / \mathrm{ml}$ morphine solution and plain tap water was initiated. Preference testing was continued for 8 days. In order to control for side preferences, the positions of the two bottles were alternated every day after they were refilled. Preference was measured by weighing both bottles each day and determining the proportion of the total liquid intake consumed in the form of morphine solution.

Group 2. Procedures were essentially the same as those described for Group 1 with the exception that the preference test was initiated at the end of 60 days of exposure to morphine solution as the only source of liquid.

\section{RESULTS}

Figure 1 shows that the average morphine consumption during the preference test was higher in Group 1 than in Group 2. An analysis of variance (ANOVA) for repeated measures (Winer, 1962) indicated that the treatment effect was significant $(\mathrm{F}=$ $6.69, \mathrm{df}=1 / 28, \mathrm{p}<.01)$ as was the repeated measures effects $(\mathrm{F}=6.40, \mathrm{df}=7 / 196, \mathrm{p}<.001)$. The Treatments by Repeated Measures interaction was also significant $(\mathrm{F}$ $=6.84, \mathrm{df}=7 / 196, \mathrm{p}<.001)$. Significantly more than $50 \%$ of the total liquid intake was in the form of morphine solution in Group $1(\mathrm{t}=5.46, \mathrm{df}=14$, $\mathrm{p}<.001$ ), indicating that a clear preference for morphine was developed. Consumption of morphine in Group 2 was also generally above 50\%, however, the mean difference was not statistically significant.

\section{DISCUSSION}

During the 8 days of preference testing, subjects in both groups continued to self-administer morphine and maintained average daily doses of $32 \mathrm{mg} / \mathrm{kg}$ and $27 \mathrm{mg} / \mathrm{kg}$ in Group 1 and 2, respectively, even though tap water was available as an alternative liquid. This self-administration of morphine was interpreted as evidence that dependency had developed in Group 1 and was in the process of developing in Group 2. These data suggest that a preference for morphine can be induced without resorting to special procedures other than forced consumption of weak solutions of morphine. The consumption differences between the two groups indicate that longer periods of enforced drinking induce stronger preferences for morphine. A period of approximately 12 weeks appears to be optimal. This relatively long induction period, during which the postingestional consequences of morphine taste were associated with the alleviation of withdrawal stress, suggests that rats are relatively unprepared to learn that the bitter morphine taste has medicinal effects.

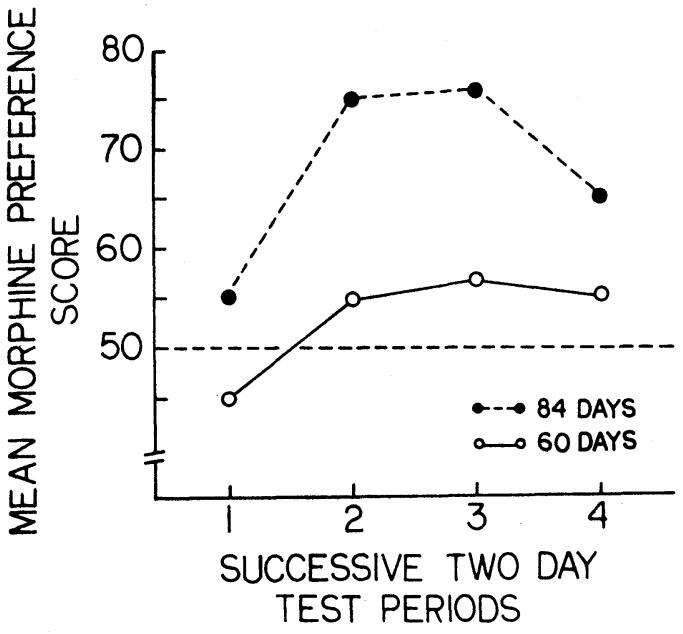

Figure 1. Group preferences for morphine after forced morphine drinking.

\section{REFERENCES}

Beach, H. D. Morphine addiction in rats. Canadian Journal of Psychology, 1957, 11, 104-112.

Ha nna, C. A demonstration of morphine tolerance and physical dependence in the rat. Archieves International Pharmacodynamics, 1960, 124, 326-329.

Huidobro, G Huidobro, J. P., \& Lorrainn, G. Tolerance to morphine in white mice. Acta Physiologia Latino Americano, 1968, 18, 59-67.

Khavari, K., \& Risner, M. Opiate dependence produced by adlibitum drinking of morphine in water, saline, and sucrose vehicles. Psychopharmacologia, 1973, 30, 291-302.

Kuma, R., Steinberg, H., \& Stolerman, I. P. Inducing a preference for morphine in rats without premedication. Nature, 1968, 218, 564-565.

Maggiolo, C., \& Huidobro, F. Administration of pellets of morphine to mice; abstinence syndrome. Acta Physiologia Latino Americano, 1961, 11, 70-78.

Martin, W. R., Wikler, A. Eades, C. G., \& Pescor, F. T. Tolerance to and physical dependence on morphine in rats. Psychopharmacologia, 1963, 4, 247-260.

Nicholes, J. R., \& Davis, W. M. Drug addiction II. Variation of addiction. Journal of the American Pharmacological Association, 1959, 48, 259-262.

Seevers, M., \& Deneau, G. Phy siological aspects of tolerance and physical dependence. In W. Root and F. Hofman (Ed.), Physiological pharmacology. New York: Academic Press, 1963.

Stolerman, I. P., \& Kumar, R. Preference for morphine in rats, Validation of an experimental model of dependence. Psy chopharmacologia, 1970, 17, 137-150.

Thompson, T., \& Ostlund. W. Susceptibility to readdiction as a function of the addiction and withdrawal environments, 1965.

Weeks, J. R. Experimental morphine addiction: Method for automatic intravenous injections in unrestrained rats. Science, $1962,138,143-144$.

Wei, B. Brain lesions attenuating "Wet Shake" behavior in morphine abstinent rats. Life Sciences, 1973, 12, 385-392.

Wikler, A., Green, P., Smith, H., \& Pescor, F. Use of a benzinidazole derivative with potent morphine-like properties orally as a presumptive reinforcer in conditioning of drug seeking behavior in rats. Federal Proceedings, 1960, 19, 22.

Wikler, A., Pescor, F., Miller, D., \& Norrell, H. Persistent potency of a secondary (conditioned) reinforcer following withdrawal of morphine from physically dependent rats. Psychopharmacologia, 1971, 20, 103-117.

Winer, B. J. Statistical principles. in experimental design. New York: McGraw-Hill, 1962.

(Received for publication December 30, 1974.) 